\title{
Turismo de base comunitária à luz da teoria ator- rede: novos caminhos investigativos no contexto brasileiro
}

Community-Based Tourism Inspired by Actor-Network Theory: New

Investigative Paths in the Brazilian Context

Tourisme de base communautaire à la lumière de la théorie de l'acteur-réseau:

des nouvelles voies de recherche dans le contexte brésilien

Edilaine Albertino de Moraes, Marta de Azevedo Irving, Rosa Maria Leite Ribeiro Pedro e Elizabeth Oliveira

\section{OpenEdition \\ Journals}

\section{Edição electrónica}

URL: http://journals.openedition.org/rccs/10761

DOI: $10.4000 /$ rccs. 10761

ISSN: 2182-7435

\section{Editora}

Centro de Estudos Sociais da Universidade de Coimbra

\section{Edição impressa}

Data de publição: 1 setembro 2020

Paginação: 145-168

ISSN: 0254-1106

Refêrencia eletrónica

Edilaine Albertino de Moraes, Marta de Azevedo Irving, Rosa Maria Leite Ribeiro Pedro e Elizabeth Oliveira, «Turismo de base comunitária à luz da teoria ator-rede: novos caminhos investigativos no contexto brasileiro », Revista Crítica de Ciências Sociais [Online], 122 | 2020, posto online no dia 10 setembro 2020, consultado o 15 setembro 2020. URL : http://journals.openedition.org/rccs/10761 ; DOI : https://doi.org/10.4000/rccs. 10761 


\section{EDILAINE ALBERTINO DE MORAES, MARTA DE AZEVEDO IRVING, ROSA MARIA LEITE RIBEIRO PEDRO, ELIZABETH OLIVEIRA}

\section{Turismo de base comunitária à luz da teoria ator-rede: novos caminhos investigativos no contexto brasileiro}

Este artigo enfoca a necessidade de uma nova problematização teórica e conceitual do turismo de base comunitária ou turismo comunitário (TBC) no Brasil, explorando a teoria ator-rede como uma via possível nesse sentido. Para tanto, propõe-se contribuir para essa reflexão por meio de um breve relato da pesquisa empírica desenvolvida na Rede Cearense de Turismo Comunitário (TUCUM - Brasil), com o objetivo de descrever as suas dinâmicas de articulação e composição do TBC. Por essa perspectiva, foi possível identificar elementos não-humanos que operam nessa rede de atores. O estudo sinalizou, ainda, a importância do conceito de associação para o rastreamento de múltiplas conexões possíveis entre os atores envolvidos no TBC, na Rede TUCUM. Assim, a teoria ator-rede permitiu analisar as dinâmicas do TBC, sublinhando os movimentos de reinvenção dessa prática no contexto brasileiro.

Palavras-chave: Brasil; teoria ator-rede; turismo de base comunitária.

\section{Introdução}

No contexto brasileiro, desde a década de 1990, iniciativas designadas como turismo de base comunitária ou turismo comunitário (de agora em diante TBC) vêm sendo delineadas a partir de estratégias culturais e políticas enraizadas localmente, frente às tendências hegemônicas do turismo massificado no Sul global.

Nesse movimento, pesquisadores brasileiros vêm afirmando que propostas de TBC se diferenciam daquelas em curso, dominadas pela lógica do mercado, principalmente, por sua origem de base endógena. Partindo da leitura crítica de alguns autores de referência nessa discussão, os debates sobre o TBC têm sido orientados, sobretudo, pela compreensão dessa prática como uma alternativa para a inclusão de populações de regiões periféricas e, também, para a valorização dos modos de vida de povos e comunidades 
tradicionais, segundo o compromisso de justiça, de solidariedade e de participação dos atores envolvidos no processo (Coriolano e Lima, 2003; Mendonça e Irving, 2004; Bartholo et al., 2009; Sampaio, 2011; Fabrino, 2013; Novo e Cruz, 2014; Scharer, 2015; Moraes e Irving, 2018).

Nessa perspectiva, o TBC tem sido tema de crescente interesse em pesquisas sociais e publicações recentes, no Brasil, conquanto essas discussões tenham traduzido também questões controversas. Isso porque as interpretações das complexas realidades e dos eventuais riscos, que precisam ser considerados em planejamento de TBC, vêm se restringindo a uma leitura idealizada e simplista das dinâmicas socioculturais, que se expressam na armadilha da "vitimização" das populações locais e/ou tradicionais envolvidas no processo. Além disso, o TBC, entendido como uma alternativa em substituição ao turismo de massa, tende a fragmentar a leitura dos seus efeitos em um contexto de economia de mercado global. Igualmente, nesse processo, pode ser provocada uma situação de redução do TBC a um negócio orientado apenas para a recepção de turistas e para a geração de renda local, tensionando, assim, as relações e as estratégias de defesa do território tradicional (Moraes, 2019).

Considerando esses antecedentes e contradições, conceitos e visões associados ao TBC não podem ser naturalizados com base em um modelo idealizado e generalizado para todo e qualquer contexto socioeconômico. Ao contrário, a problematização sobre o TBC requer olhares ancorados nas práticas locais e perpassados pela pluralidade de saberes e vozes que se articulam e tecem as dinâmicas socioculturais (ibidem). Mas no que consiste o TBC? Quais são os atores que se mobilizam em torno dessa prática? Afinal, do que é produzido o TBC?

Propõe-se, neste artigo, contribuir para essa reflexão temática, a partir de um breve relato da pesquisa empírica desenvolvida em Moraes (ibidem). Nesse sentido, busca-se descrever as dinâmicas de articulação e composição do TBC, relacionadas à experiência brasileira Rede Cearense de Turismo Comunitário (TUCUM). A importância dessa iniciativa pioneira, lançada em 2008, deve-se à articulação entre diversos grupos de pescadores artesanais, etnias indígenas, agricultores familiares, camponeses, quilombolas e moradores de periferias urbanas, localizados de leste a oeste na Zona Costeira Cearense - umas das regiões mais visitadas e disputadas no país, onde esses grupos lutam pelo desenvolvimento do turismo comunitário e em defesa do fortalecimento do território tradicional e de seus direitos.

Para investigar tal temática, a abordagem teórico-metodológica adotada foi a teoria ator-rede (Actor-Network Theory - ANT, na versão original em inglês), apoiada, sobretudo, nos trabalhos do sociólogo Bruno Latour, 
seu principal expoente. A escolha pela ANT se justifica, em síntese, por esta propor um caminho inovador para a abordagem do "social", reconhecendo, para tanto, as redes constituídas de elementos humanos e não-humanos. Vale ressaltar que, apenas há cerca de uma década, a ANT tem sido adotada como dispositivo teórico-metodológico de análise da produção do turismo, sem incidir, especificamente, sobre o TBC. Nesse contexto, a maioria dos estudos tem sido registrada, principalmente, na Europa (van der Duim, 2005; Rodger et al., 2009; van der Duim et al., 2012; Dedeke, 2017, entre outros). Portanto, na literatura especializada, a problematização sobre o TBC no Brasil à luz da ANT ainda é incipiente.

Partindo dessa lacuna, este exercício investigativo tem como principal diretriz metodológica "seguir os próprios atores" e se alimentar de controvérsias, sem tentar resolvê-las (Latour, 2012: 31). Além disso, em processos de construção de conhecimento à luz da ANT, deve-se caminhar com menos certezas e menos hipóteses, o que não significa deixar de ser ético e criterioso quanto à orientação metodológica da pesquisa.

Assim, segundo Latour (2012), o caminho da ANT deve ser trilhado de forma experimental, provisória e ensaística. Com enfoque antropológico, a metodologia adotada envolveu, principalmente, pesquisa bibliográfica e documental sobre o TBC no contexto brasileiro e sobre a própria ANT. Além disso, foi realizada pesquisa de campo, de novembro de 2015 a novembro de 2017, considerando, nesta reflexão, parte dos dados de entrevistas e conversas informais com lideranças comunitárias e assessores de organização não governamentais, assim como de observação participante em assembleias gerais da Rede TUCUM.

Dessa forma, ao procurar ensaiar a pertinência da ANT para a compreensão mais profunda, ampla e múltipla do TBC, busca-se refletir, também, sobre como o contexto brasileiro tem representado um laboratório de experiências emergentes para resistir e fazer frente às limitações dos estudos nesse campo. Nessa perspectiva, o TBC se expressa como fonte inspiradora de alternativas diante das desigualdades sociais existentes, bem como da condição estratégica de sociobiodiversidade e riqueza cultural do país, em face de interesses geopolíticos mundiais.

\section{Turismo de base comunitária: debates e perspectivas analíticas no contexto brasileiro}

As discussões sobre o TBC, no Brasil, têm sido estimuladas e construídas, nos últimos anos, em espaços formais e informais de debate coletivo. Assim, inúmeros atores vêm sendo envolvidos, entre os quais as universidades, os movimentos sociais, as organizações não governamentais, as instituições 
governamentais, as agências de cooperação internacional e, principalmente, as lideranças comunitárias articuladas à defesa de direitos de povos e populações tradicionais.

No plano acadêmico, os debates sobre o TBC vêm encontrando terreno fértil, sobretudo nos Encontros Nacionais de Turismo de Base Local (ENTBL), desde a realização de sua primeira edição, em 1997, na Universidade de São Paulo, tendo sido a última edição promovida na Universidade Federal de Pernambuco, em 2018. Esses eventos proporcionaram uma oportunidade ímpar para a reflexão crítica sobre a práxis associada ao turismo, agregando olhares de diferentes áreas do conhecimento.

Quanto ao papel desenvolvido pelo movimento social nesse debate, uma iniciativa reflexiva de referência tem sido o Fórum Social Mundial (FSM), realizado desde 2002, quando esse evento foi lançado em Porto Alegre. Desde então, tornou-se itinerante, percorrendo diferentes continentes até a sua última edição, em 2018, quando retornou ao Brasil e foi realizado em Salvador (Bahia). Nas edições do FSM foi possível trazer para a cena principal profundos questionamentos político-ideológicos sobre o processo de globalização, tendo também sido discutidas propostas contra-hegemônicas que pudessem orientar novos caminhos para o desenvolvimento. No caso do turismo, reconheceu-se, sobretudo, a sua importância como uma possível via para a transformação social.

Com relação à atuação das organizações não governamentais, é importante mencionar como referência, no plano nacional, o Encontro Nacional da Rede Brasileira de Turismo Solidário e Comunitário (TURISOL), que ocorreu primeiramente em 2010, em Uruçuca (Bahia), e o segundo em 2015, na capital federal Brasília, visando contribuir para esse debate e para a expansão dessa prática por meio da promoção de intercâmbio de conhecimentos e de negócios.

Nesses encontros foram pactuadas ações para a construção de alternativas dirigidas ao turismo em bases sustentáveis - dentre as quais o TBC, orientado, desde a origem do debate, pelo compromisso de práticas sustentáveis e solidárias. Dessa forma, esses fóruns representaram oportunidades para a expressão de movimentos de resistência ao modelo hegemônico capitalista, que se manifesta também na práxis turística. Assim, busca-se provocar o setor governamental para o estabelecimento de novas diretrizes de políticas públicas e a promoção de ações inovadoras na racionalidade contra-hegemônica do turismo.

Nesse sentido, os Seminários Internacionais de Turismo Sustentável (SITS), cujas edições ocorreram em 2003 e 2008 em Fortaleza (Ceará), 
representaram marcos para a construção do TBC (Scharer, 2015). As duas edições desse evento se constituíram em momentos férteis para as reflexões acerca do tema e para os intercâmbios de experiências entre pesquisadores, lideranças de comunidades tradicionais e interlocutoras de instituições governamentais e não governamentais. As publicações e anais deles resultantes (Coriolano e Lima, 2003; Lima e Coriolano, 2003; Silva et al., 2008) sistematizaram diversos resultados dos debates realizados, que contribuíram para que a terminologia turismo comunitário se afirmasse nacionalmente e se tornasse foco de interesse de pesquisas acadêmicas em todo o país. Foi também a partir das reflexões sobre esse tema, no âmbito do I SITS, que Coriolano e Lima (2003) enunciaram alguns princípios para o desenvolvimento de projetos com esse direcionamento:

a) o turismo comunitário deve ser conduzido de modo integrado às demais atividades econômicas, fortalecendo a agricultura, a pesca artesanal e o artesanato;

b) a geração de emprego e renda deve ser priorizada para os residentes nas comunidades envolvidas, os pequenos empreendimentos locais, a dinamização do capital local, a garantia da participação de todos, com espaço assegurado às mulheres e aos jovens;

c) a participação das comunidades deve ser garantida a partir do planejamento descentralizado e com o desenvolvimento de uma política de turismo em bases locais;

d) a luta pela regulamentação fundiária e a posse da terra pelas comunidades indígenas e pesqueiras devem ser apoiadas, além de assegurada a regulamentação das unidades de conservação da natureza.

A definição desses princípios como pontos de partida para os projetos de TBC representou um passo importante para o delineamento dos fundamentos do que viria a se expressar, posteriormente, como turismo de base comunitária. Por outro lado, ainda que se reconheça a importância de iniciativas dessa natureza, inúmeros são ainda os desafios a serem enfrentados em um país de dimensões continentais como o Brasil, sujeito, historicamente, às desigualdades regionais.

Nesta retrospectiva de construção de bases consolidadas sobre esse debate, vale destacar a pesquisa de Mendonça et al. (2014), realizada entre 2002 e 2014, com o objetivo de investigar, do ponto de vista teórico-conceitual e político-organizacional, o TBC no Brasil. Esse estudo resultou no mapeamento de 206 iniciativas de TBC, citadas em produções acadêmicas, localizadas em quase todos os estados brasileiros. Segundo essa pesquisa, é possível afirmar que a maioria das experiências de TBC surgiu em áreas rurais de elevada diversidade biológica, nas quais vivem diferentes 
grupos humanos que ali exercem as suas atividades produtivas tradicionais e, mais recentemente, expandiu-se para as áreas urbanas caracterizadas como favelas.

Além disso, no plano conceitual, segundo Mendonça et al. (2014), em geral, o TBC envolve iniciativas cujos benefícios socioeconômicos impactam diretamente as comunidades locais, nas quais se busca a sustentabilidade social e econômica, conforme o compromisso das relações dialógicas entre os turistas e as comunidades anfitriãs envolvidas. Nessas iniciativas há o reconhecimento do protagonismo das comunidades locais, assim como a prevalência da gestão comunitária no processo. O movimento coletivo pela busca por desenvolvimento local, pelo fortalecimento do sentido de pertencimento, pela afirmação das identidades locais e pelo respeito às tradições e valorização cultural constituem também eixos comuns dessas iniciativas. O TBC é ainda entendido como complemento e não como substituição às demais atividades produtivas locais.

$\mathrm{Na}$ perspectiva conceitual e política, o TBC tem sido também associado ao sentido das lutas dos movimentos de resistências relacionados aos direitos à posse da terra, de acesso e uso dos recursos naturais e ao local herdado (Santiago, 2015), um contexto característico de muitas regiões periféricas nas quais as populações tradicionais se veem ameaçadas pelos processos de apropriação de seus territórios pelo capital hegemônico, inclusive pela via do turismo.

Por essas perspectivas de análise, a compreensão do TBC representa um contraponto aos modelos de desenvolvimento turístico inspirados pelas premissas de crescimento econômico e pela lógica do mercado, nos quais prevalece o foco na produção, na competitividade e no lucro. Sendo assim, na percepção de Sampaio (2011), o principal desafio para o desenvolvimento do TBC seria o compromisso de salvaguarda dos modos de vida tradicionais, a partir da reafirmação das dinâmicas socioculturais locais inseridas em economias comunitárias, porém capazes de dialogar com a economia de mercado global.

Além disso, é fundamental que seja desmistificada a leitura simplista e estereotipada do TBC como uma prática na qual um grupo desfavorecido recebe, em seu convívio cotidiano, pessoas curiosas pelo exotismo local apenas para aumentar a sua renda e melhorar a sua qualidade de vida. O TBC só acontecerá, efetivamente, se estiver baseado em uma perspectiva dialogal entre turistas e comunidades anfitriãs (Irving, 2009).

Pode-se também relacionar o TBC a um contexto de alianças entre redes de organizações comunitárias, organizações não governamentais (ONG), igrejas, universidades, agências e operadoras de viagens, entre outros atores. 
Essas redes são formadas, geralmente, em regiões periféricas, com o objetivo de apoiar e estimular a difusão e/ou comercialização do TBC, bem como a definição de estratégias para enfrentar a condição de negligência da esfera pública com relação a esse tipo de turismo, frequentemente desvalorizado em políticas públicas (Maldonado, 2009; Cañada, 2015; Moraes et al., 2018).

Embora alguns consensos teóricos sejam observados na literatura especializada, para Lima (2011) sua leitura é ainda polêmica, ingênua e inclinada a traduzir um modelo idealizado de desenvolvimento do turismo. Por outro lado, segundo Fabrino (2013), as publicações acadêmicas brasileiras com esse enfoque não apresentam dados mensuráveis sobre a viabilidade financeira desses empreendimentos. Essas publicações tampouco abordam questões como o fluxo turístico, as taxas de ocupação dos meios de hospedagem, os processos de gestão, além da real contribuição do TBC para a melhoria das condições de vida locais. Ademais, são limitadas as abordagens teóricas e aplicadas capazes de contribuir com subsídios efetivos às políticas públicas e/ou à avaliação dos resultados obtidos.

Importa também enfatizar que o TBC, no âmbito do Ministério do Turismo, é ainda traduzido como mais uma segmentação do mercado turístico (Brasil, 2008; Silva et al., 2009). Essa perspectiva de análise encontra ressonância, sobretudo, em Mielke (2010), que defende a necessidade de profissionalização das comunidades envolvidas por meio da adoção de um modelo de gestão e organização empresarial, baseado em sistemas de eficiência e competitividade de mercado. Nesse sentido, em contraponto a todo o debate crítico sobre o tema, a discussão sobre TBC vem, paulatinamente, no plano das políticas públicas, abarcando sentidos próprios da lógica de mercado, pelos quais essa prática também vem sendo considerada como uma oportunidade de negócio.

Diante dessas controvérsias, pode-se afirmar que, embora se reconheçam alguns avanços sobre o tema, ainda prevalecem na produção acadêmica especializada em TBC perspectivas baseadas na polaridade entre o compromisso "social" e o reconhecimento da importância econômica dessa prática. Contudo, outras questões se colocam: Como abordar o TBC para além dos conceitos concebidos a seu respeito? Como é possível apreender e descrever a realidade em transformação no TBC? Em que medida a teoria ator-rede poderia contribuir para ampliar essa leitura?

\section{Teoria ator-rede: proposições e procedimentos para orientar a reflexão}

A teoria ator-rede (ANT) foi formulada a partir de meados da década de 1980, no âmbito dos Estudos de Ciência, Tecnologia e Sociedade (CTS), como resultado de um amplo esforço de pesquisa de um grupo de 
investigadores do Centro de Sociologia da Inovação da Escola Nacional Superior de Minas de Paris (França), dentre os quais se destacam Bruno Latour, John Law, Madeleine Akrich e Michel Callon, influentes teóricos contemporâneos. ${ }^{1}$ Desse grupo, nesta reflexão optou-se por seguir as orientações de Bruno Latour, um dos principais expoentes da ANT na atualidade.

Influenciando análises em diversas áreas do conhecimento, a ANT constitui um movimento de renovação das Ciências Humanas e Sociais que questiona a visão dicotômica entre natureza e sociedade, propondo um caminho inovador para a abordagem do "social" e da "sociedade" no reconhecimento de redes entrelaçadas de elementos humanos e não-humanos.

Inspirada pela perspectiva etnográfica da Antropologia, a ANT não busca explicar a realidade social, no sentido comum de apresentar um quadro consolidado de referência teórica posto à mão para ser aplicado. Ao contrário, a realidade é localizada histórica, cultural e materialmente, não sendo entendida como resultado de um contexto supostamente estável, linear e determinado.

Nesse sentido, a ANT foi concebida na busca pela superação da naturalização dos fatos sociais, promovendo exatamente a sua desestabilização. ${ }^{2}$ Afastando-se dos autores da tradição sociológica, Latour (2012) advoga não ser mais possível se pensar sobre as dinâmicas sociais, sem que se apreendam as conexões existentes entre elementos humanos e não-humanos. Isso porque um dos postulados da ANT é que, quando um humano age, mais alguém/ /alguma coisa está agindo em conjunto.

Sendo assim, pela ótica da ANT, tanto humanos quanto não-humanos são actantes, ou seja, ambos têm agência, "fazem-fazer". Para o autor, os próprios atores constroem tudo, inclusive os seus próprios quadros, contextos e teorias, o que implica deixar de lado as "molduras teóricas". Simbolicamente, o ator nunca está sozinho ao atuar no palco. Portanto, "o ator, na expressão hifenizada ator-rede, não é a fonte de um ato e sim o alvo móvel de um amplo conjunto de entidades" (ibidem: 75), que se reúne

\footnotetext{
${ }^{1}$ Os Estudos CTS desconstroem a visão ocidental hegemônica de uma ciência neutra e universal e se dedicam a investigar as relações entre ciência, tecnologia e sociedade, defendendo ser impossível compreendê-las separadamente. Esses estudos vêm fazendo uso extenso da metodologia etnográfica, o que vem repercutindo também na denominação do campo como Antropologia da Ciência e da Tecnologia. Neste campo, a abordagem da ANT é também conhecida como Sociologia da Tradução (Akrich et al., 2006).

${ }^{2}$ Essa problematização da relação natureza-sociedade foi anunciada no livro seminal Jamais fomos modernos, no qual Latour (2013: 16) expõe que o mundo é tecido por uma proliferação de "misturas entre gêneros de seres completamente novos, híbridos de natureza e cultura", que se articulam e formam não mais uma sociedade, mas uma rede sociotécnica, um conceito que imprime originalidade ao pensamento latouriano.
} 
em sua direção. Por essa razão, para a ANT, atores não são aqueles que apenas ocupam um lugar, mas sim aqueles que realizam algo e marcam uma diferença, fazendo com que outros elementos se movam a partir de suas capacidades de associações.

Assim, os mais variados atores deixam rastros no caminho, que proporcionam informação para a pesquisa. Se não atuassem dessa forma, os elementos integrantes dessas dinâmicas não seriam atores, e sim meros "intermediários", "marionetes" ou, ainda, projeções simbólicas. Nesse contexto, os atores reunidos para a ação são aqueles que devem ser incluídos em uma descrição sobre o mundo social (Latour, 2012: 213), podendo ser esses conceitos, pessoas, instituições, coisas, animais, objetos, máquinas, legislação, etc. Todavia, a ação não é "coerente, controlada, bem acabada e bem delineada". Por definição, a ação é deslocada (ibidem: 76), produzindo novas associações.

Nesse sentido, um dos principais diferenciais da ANT com relação à abordagem sociológica clássica é considerar também os elementos não-humanos na produção de realidades, para que se possa entender como uma rede é constituída. Nesse contexto, o foco se desloca do "social", entendido como um lugar de troca entre atores humanos, para as associações entre humanos e não-humanos, partícipes dessa rede sociotécnica. ${ }^{3}$

É partindo desse direcionamento que Latour (2012) propõe uma "sociologia de associações”. O autor desafia o vício cartesiano de abordar o social como adjetivo, isto é, de se debruçar sobre os chamados fatos sociais já estabelecidos, sustentando que o social precisa ser descrito a partir do que é observável. Com esse apelo, defende-se uma visão do social como um tipo de associação momentânea entre elementos humanos e não-humanos, caracterizada pelo modo como, continuamente, eles se agregam e assumem novas formas.

A ANT preconiza, assim, "reagregar" o social, isto é, "todos os elementos heterogêneos precisam ser reunidos de novo em uma dada circunstância” (ibidem: 23) para que possam continuar a existir. Essas associações entre humanos e não-humanos têm como efeito a constituição de um "coletivo" que traduz o agrupamento de todas as partes interessadas no contexto investigado. ${ }^{4}$

\footnotetext{
${ }^{3}$ A noção de associação estende e modifica o sentido das palavras social e sociedade, que, em vez da distinção entre os humanos e não-humanos, recupera conjuntamente as ciências naturais e as ciências sociais (Latour, 2004).

${ }^{4}$ Latour (2004: 117) usa o termo coletivo "para assinalar uma filosofia política na qual não há mais dois elementos que atraem: um que faria a unidade sob a forma da natureza, e outro que guardaria a multiplicidade sob a forma das sociedades". Embora empregado no singular, o termo não remete à unidade já feita, mas a um procedimento para coligar as associações de humanos e não-humanos que permitem a composição de um mundo comum.
} 
Latour (2004) coloca em relevo o coletivo das coisas, dos humanos, da natureza, da sociedade e da política, para uma discussão pública dos problemas da atualidade, que favorece um olhar aprofundado sobre as grandes questões que movem as decisões políticas. Porém, não se trata aqui de uma reflexão "crítica", denunciando as falhas e encerrando as disputas pelas determinações causais. Ao contrário, Latour (2002) explicita que uma investigação deve ser situada de forma aberta, circunstancial e incerta para ser correntemente discutida e contrariada tanto pelos pesquisadores como pelos próprios pesquisados.

Por essa abordagem, o coletivo constitui um campo de forças em constante embate, que, vez por outra, estabiliza-se de alguma forma. Esse princípio implica o entendimento de uma noção fundamental - a noção de rede - que está relacionada à existência de vários fios que conectam o social sem necessariamente formar uma unidade, mas configurando um processo contínuo de associações. A rede de atores é aberta e heterogênea, possibilitando o estabelecimento de todo e qualquer tipo de conexão. Mas estar conectado ou interconectado e ser heterogêneo não é suficiente. Tudo depende do tipo de ação que está fluindo nas associações entre elementos humanos e não-humanos.

Latour (2013: 9) afirma ainda que as redes atravessam a fronteira entre os grandes feudos da crítica, sendo simultaneamente "reais como a natureza, narradas como o discurso, e coletivas como a sociedade", sendo exatamente essa dinâmica que configura as tramas sociotécnicas que enredam a sociedade. Portanto, a rede sociotécnica constitui o campo de produção do conhecimento sobre algo, no qual todos os elementos se articulam sobre o objeto de interesse, mobilizando diversas vozes.

Com base nesse aporte, Pedro (2010) argumenta que pensar sobre as redes, tal como elas vão se performando, implica, sobretudo, "pensar com a rede”. Nesse processo investigativo, são enfatizados o trabalho, o movimento, o fluxo e as mudanças resultantes de associações (Latour, 2012). Sob esse ponto de vista, na noção de rede se considera que o importante não é somente abordar os vínculos e alianças, mas também os efeitos gerados por esses vínculos e as implicações de tais alianças em ação.

O desafio da pesquisa sobre redes, conforme as pistas da ANT, é, portanto, seguir e transpor os "rastros" deixados pelos atores, considerando os seus agenciamentos e as controvérsias existentes. Ademais, busca-se rastrear o fluxo das conexões entre as controvérsias, sem intervalos, e não propriamente tentar decidir como resolvê-las. De outra forma, Latour (ibidem) discute que os pesquisadores em ANT devem seguir com paciência esses rastros, 
ater-se aos mediadores da ação, ouvir o que têm a dizer, desviando-se das generalizações apressadas, que podem recair na purificação dos fatos.

Segundo a ANT, não se deve confundir a rede que é delineada pela descrição com aquela utilizada para fazer a descrição. Dessa maneira, entende-se que a rede não é o "desenho", mas o "lápis" que a desenha. Por essa razão, refere-se ao movimento de desenhar e não, propriamente, a uma rede desenhada. Partindo dessa compreensão e com o propósito de se pensar em uma dinâmica em rede, propõe-se, simplesmente, descrever as conexões que estão à mão do pesquisador e, também, o que os atores fazem para expandir, relacionar, comparar e organizar, sem impor sobre eles uma definição a priori sobre as suas capacidades de construção do mundo (Latour, 2012).

Assim, considerando as propostas que emergem da ANT, em síntese, três pistas metodológicas foram fundamentais para a orientação da presente investigação: 1) reconhecer elementos humanos e não-humanos como atores no processo; 2 ) observar a produção de uma "rede", envolvendo as partes interessadas, possibilitando um processo contínuo de associações; e 3) seguir os atores em ação, que Latour (2012) considera terem força para "fazer-fazer", a partir de incertezas e não de conceitos pré-estabelecidos, categoricamente. Tendo em vista que a ANT defende a pesquisa de campo, essas pistas contribuíram para provocar reflexões acerca de como fazer pesquisa e construir conhecimento sobre a realidade no TBC, encontrando possibilidades e limitações em sua prática. Dessa maneira, quais foram as contribuições dessas bases da ANT para inspirar novas leituras com relação ao TBC estudado empiricamente no contexto da Rede TUCUM?

\section{A ANT como uma via de análise para o TBC na Rede TUCUM}

Neste exercício inspirado pela ANT, foi possível rastrear que a Rede Cearense de Turismo Comunitário TUCUM (doravante designada por Rede) vem se constituindo desde 2003 na primeira tentativa de se organizar uma rede no Ceará. Esta envolve experiências de integração de roteiros de turismo comunitário, com a facilitação da parceria entre o Instituto Terramar, a Associação Amigos da Prainha do Canto Verde (AAPCV), da Suíça, a Associação Tremembé Onlus, da Itália, além de organizações não governamentais de ampla atuação em projetos sociais na Zona Costeira Cearense (ZCC). ${ }^{5}$

\footnotetext{
${ }^{5}$ Sob a liderança da Prainha do Canto Verde (Beberibe, Brasil), a Rede TUCUM tem sido impulsionada, pela participação e articulação com diferentes grupos de turismo comunitário, redes, organizações não governamentais e fóruns atuantes na região.
} 
Mas, apenas em 2008, ocorreu o lançamento oficial da Rede, durante o II Seminário Internacional de Turismo Sustentável (Fortaleza/CE). Esse processo transpassou reflexões sobre as questões estruturantes para a sua organização, promovendo ações de intercâmbio, articulação e integração com representantes de outros movimentos de turismo comunitário, como a Rede Brasileira de Turismo Solidário e Comunitário (TURISOL) e a Rede de Turismo Comunitário da América Latina (REDTURS).

$\mathrm{Na}$ construção da Rede, foram definidos oito princípios para nortear a proposta desejada de turismo, dentre os quais um se destaca: as atividades de turismo devem ser desenvolvidas por grupos organizados, sendo que os projetos devem ser coletivos e de base familiar (TUCUM, 2010). Com esse enfoque, o turismo comunitário se traduziu, para a Rede, "na capacidade de os grupos organizados possuírem o controle efetivo sobre o seu desenvolvimento, sendo diretamente responsáveis pelo planejamento das atividades e pela gestão das infraestruturas e dos serviços turísticos" (Martins, 2013: 5). Além disso, defendeu-se que o turismo comunitário seja desenvolvido de modo integrado à dinâmica produtiva local, orientando relações comerciais e de intercâmbio, com base na ética e na solidariedade, para a geração e a distribuição equitativa da renda e a valorização da produção, da cultura e das identidades locais.

Dessa forma, foi acordado, em 2013, o Caderno de Normas e Procedimentos Internos da Rede, considerando dois principais objetivos de ação: "oferecer aos viajantes responsáveis de todo o mundo a oportunidade de conhecer e vivenciar experiências de turismo comunitário"; e, ao mesmo tempo, "promover formas de oferta turística locais para garantir às populações tradicionais a permanência em seu território e possibilitar a continuidade das atividades econômicas tradicionais" (em particular, a pesca e a agricultura), dando visibilidade às lutas sociais para o reconhecimento das comunidades participantes (Martins, 2013: 8). ${ }^{6}$

Nessa direção, diversos grupos comunitários exercendo diferentes papéis vêm performando o processo de construção da Rede, nomeadamente: pescadores artesanais, etnias indígenas, além de camponeses, agricultores familiares, marisqueiras, assentados rurais e moradores de periferias urbanas. $\mathrm{Na}$ sua atual composição, esses grupos articulam o processo em 11 lugares de turismo comunitário: 1) Tatajuba - Camocim; 2) Curral Velho - Acaraú; 3) Assentamento do Maceió - Itapipoca; 4) Caetanos de Cima - Amontada;

\footnotetext{
${ }^{6}$ As atividades ofertadas abrangem pousadas comunitárias e familiares, além de quartos nas residências dos próprios moradores; experiências de culinária regional com peixes, frutos do mar e animais de criação; trilhas e passeios ecológicos; pacotes para festas culturais tradicionais e infraestrutura para a realização de eventos.
} 
5) Terra Indígena Lagoa da Encantada do povo Jenipapo Kanindé - Aquiraz;

6) Reserva Extrativista do Batoque - Aquiraz; 7) Reserva Extrativista da Prainha do Canto Verde - Beberibe; 8) Assentamento Coqueirinho Fortim; 9) Ponta Grossa - Icapuí; 10) Quilombo do Cumbe - Aracati; e 11) Vila da Volta - Aracati. Três grupos de apoio integram ainda a Rede: o Centro de Formação, Capacitação e Pesquisa Frei Humberto do Movimento dos Trabalhadores Rurais Sem Terra - Fortaleza; a Pousada Tremembé Icapuí; e a Vila dos Poetas - Maranguape. Já da assessoria institucional participam duas organizações: o Instituto Terramar - Fortaleza, que apoia as comunidades localizadas no litoral oeste, e a Associação Caiçara de Promoção Humana - Icapuí, com ações relacionadas diretamente às comunidades do litoral leste cearense.

Nesse contexto, ao longo de dez anos, uma das principais dificuldades enfrentadas pela Rede tem sido alcançar um fluxo regular de visitantes, o que tem gerado incertezas no debate sobre as suas reais possibilidades e sobre as capacidades de atuação local em favor do coletivo. Dessa forma, a Rede vem reunindo muitos interesses no TBC, envolvendo questões, dinâmicas e demandas de acordo com a realidade de cada grupo comunitário local.

Por sua vez, um entendimento comum da maioria dos porta-vozes das comunidades locais e das ONG pesquisadas se refere a como esse movimento vem impulsionando e fortalecendo as articulações de estratégias para as lutas em defesa dos territórios tradicionais, que tiveram origem no final da década de 1980. Mas, reconhecendo a necessidade de ampliação das ações realizadas, foi também possível observar outras leituras que permitiram considerar o TBC como um conceito difícil de definir com precisão.

No que concerne ao funcionamento da Rede, a sua condição informal provocou a ideia de transformá-la em uma instituição que pudesse viabilizar efetivamente a comercialização direta do TBC. No entanto, esse debate foi polêmico em todo o período da pesquisa. Por um lado, a proposta de criação de uma empresa ou de uma agência de turismo e, até mesmo, o desejo de apropriação de padrões adotados convencionalmente para a gestão e a operação de serviços turísticos foram defendidos como uma via possível para a manutenção da Rede. Por outro, as atuais investidas de empresas externas à realidade local - para se apoderarem do TBC apenas como uma oportunidade de negócio promissor - foram reveladas como uma ameaça.

A compreensão sobre o TBC como um negócio propriamente dito foi uma perspectiva considerada, por algumas lideranças comunitárias, quase como uma heresia e uma violação do Caderno de Normas e Procedimentos Internos, elaborado justamente para ser adotado e respeitado pelos grupos locais. Esse tipo de visão provocou tensões no relacionamento entre 
alguns atores, intensificando o movimento para a formulação de estratégias de resistência e captura à possibilidade de o TBC ser reduzido a um negócio orientado apenas para a recepção de turistas e para a geração de renda local.

Desta forma, a Rede tem contribuído para que os grupos comunitários construam, juntamente com outros atores envolvidos, uma multiplicidade de versões do TBC, em vez de apenas diretrizes, características e dimensões do processo. Essa diversidade surge a partir de diferentes olhares e maneiras de conceber a realidade dessas localidades. Isto é, os atores locais trazem consigo sabedorias, histórias, hábitos e preocupações peculiares, que intervêm no processo de busca por soluções criativas para as mudanças que as comunidades locais vêm enfrentando e, ao mesmo tempo, produzindo no seu percurso. Nesse caso, as resistências e a busca por novas formas de inserção no mercado turístico têm sido articuladas sem perder ou desconsiderar os princípios em transformação do TBC.

Assim, foi possível ensaiar um modo de análise da Rede não apenas centrado em seu poder de resistência ou em sua importância econômica. Ou seja, o turismo comunitário se traduz ora como estratégia de resistência, ora como oportunidade de negócio. A apreensão desses discursos simultâneos e recorrentes permitiu reconhecer a multiplicidade ontológica associada ao turismo comunitário, que se produz e se agrega nas diversas conexões entre as estratégias de resistência e de negócio.

No entanto, considerando que a perspectiva da ANT é ainda incipiente na pesquisa acadêmica sobre o TBC, um longo caminho de aprendizagem de novas práticas investigativas deve ser ainda percorrido. Para a argumentação a favor da experimentação da ANT - uma via ontológica e epistemológica capaz de não apenas construir uma base teórica, mas, sobretudo, indicar pistas para a ação teórico-prática -, propõe-se a articulação entre os elementos não-humanos, o processo de associações e os atores em ação.

\section{a) Os elementos não-humanos no TBC}

Em contraposição à premissa de que o humano seja o centro das questões nos estudos em turismo (Netto, 2011), a proposta da ANT agrega a importância dos elementos não-humanos à reflexão. Isso porque, nessa perspectiva, pressupõe-se que a compreensão sobre o ser humano só pode ser apreendida quando os não-humanos estão também no centro do debate sociológico. Considerando essa premissa orientadora da ANT, os pesquisadores interessados nos estudos sobre o TBC estariam convidados a colocar em xeque a crença de que esta prática se configura apenas por meio da dinâmica entre os atores humanos. Esse deslocamento poderia 
contribuir para a análise das articulações dos humanos com os não-humanos envolvidos, assim como das ações que estes últimos poderiam gerar no processo de TBC.

Nessa direção, poder-se-ia considerar, com base na pesquisa empírica realizada na Rede TUCUM, o argumento de que o TBC se articula às demais atividades produtivas de um determinado lugar turístico, as quais, por sua vez, manifestam-se nas práticas cotidianas locais. Essas atividades podem ser ilustradas pelas produções da agricultura familiar, quintais produtivos agroecológicos, pescarias artesanais, mariscagens, confecção das rendas de bilros e de bijuterias de sementes indígenas, artes da culinária regional, regatas ecológicas, feiras da economia popular solidária, entre tantas outras ações nos lugares de TBC investigados. Assim, esses elementos não-humanos traduzem, conjuntamente, a natureza, a cultura e as técnicas envolvidas em seu desenvolvimento. Isso porque, pela perspectiva da ANT, esses elementos constituem "híbridos sociotécnicos" capazes de mobilizar ações nas dinâmicas em transformação, não se restringindo apenas a representar objetos ou projeções simbólicas que imprimem significados.

Sobre os elementos não-humanos constitutivos do processo de TBC, é importante ressaltar, ainda, que os recursos naturais preservados, como praias, dunas, lagoas, mangues, falésias, mares e matas, comumente considerados como pontos focais de interesse turístico, são capazes igualmente de gerar efeitos nas dinâmicas onde as comunidades da Rede TUCUM estão situadas. Isso porque compõem processos permeados por conflitos e contradições que envolvem, por exemplo, a disputa entre os inúmeros interesses relacionados à regularização da situação dos territórios de todos os grupos comunitários, às dinâmicas de proteção da natureza - por meio da criação de áreas protegidas em seus locais herdados -, e ao próprio mercado turístico, que contribui para a impulsão da especulação imobiliária, do turismo de veraneio e da urbanização nessas áreas de inserção da Rede.

Por esta perspectiva, além de se reconhecer a importância dos elementos não-humanos no movimento do TBC, buscou-se acompanhar, empiricamente, como as conexões entre os distintos atores e as inúmeras questões envolvidas nessa prática impulsionaram as diferentes ações na configuração da Rede. Dessa maneira, foi possível compreender os elementos heterogêneos rastreados pela pesquisa como produtos da rede sociotécnica do TBC, em contraposição à sua investigação como categorias explicativas estabilizadas. 


\section{b) O TBC como um processo de associações}

A noção de associação pela perspectiva da ANT teve importância central para dar sustentação aos argumentos aqui defendidos, na medida em que possibilitou a ampliação da análise em foco e a consideração das múltiplas conexões possíveis entre os atores envolvidos no TBC da Rede. Isso implicou apreender o TBC, simultaneamente, como um discurso e uma prática, o que exigiu se pensar em uma multiplicidade de políticas e ontologias, para além daquelas vinculadas diretamente ao turismo. Ou seja, a compreensão do TBC transcendeu a perspectiva de planejamento e estruturação de empreendimentos comunitários ou a mera dinâmica de recepção de visitantes, envolvendo múltiplos atores e interesses que produziram as associações e as dissociações entre os elementos heterogêneos, articulando-se nesse movimento de delineamento da rede sociotécnica.

Isso significa que foram rastreados alguns atores das comunidades locais, dos empreendimentos de hospedagem e alimentos e bebidas, lideranças das associações de moradores do lugar turístico, articuladores dos movimentos sociais ali atuantes, além de coordenações das ONG que prestam assessoria local e de outros atores que eles fizeram circular no coletivo. Nesse sentido, as ações dos atores heterogêneos dispostos na rede sociotécnica do TBC permitiram descrever a produção de associações na Rede.

Diante das reflexões que emergiram desse exercício inspirado na ANT, algumas questões centrais se revelaram na pesquisa, no sentido de orientar um olhar mais atento, aberto e detalhado para a apreensão das associações no TBC. Para tal, seria importante observar, ainda, como são enunciadas e explicitadas questões do tipo: Com que atores humanos e não-humanos os grupos locais se interessam em se associar? No caso da Rede, com que partidos políticos, ONG, movimentos sociais, órgãos públicos e agências de turismo seria interessante se enredar? Além disso, quais são as ligações que se estabelecem entre essas instâncias e que novas associações poderiam ser produzidas no TBC em rede? Isso implicaria entender como são produzidas as resistências e as capturas nessas associações contínuas, bem como identificar as mais diversas práticas de TBC que poderiam ser traduzidas a partir da dinâmica de investigação proposta.

Essas questões tendem a reafirmar, uma vez mais, que a investigação sobre o TBC, na perspectiva da ANT, e, particularmente, das associações, pressupõe a compreensão do modo pelo qual as conexões são articuladas entre a base referencial teórica inspiradora, as expressões culturais e os modos de existência dos atores envolvidos nessa prática. Para tanto, é importante que se considerem, nesse processo, os saberes acadêmicos, 
os saberes populares e outras formas de produção de conhecimento como elementos co-construtores de uma mesma realidade sociotécnica.

Um argumento que poderia ilustrar essa afirmação se refere à própria premissa da Rede centrada na afirmação do protagonismo e na participação de comunidades locais no processo de planejamento e gestão do TBC. Porém, pela perspectiva da ANT, não se poderia restringir a leitura ao âmbito da dinâmica da comunidade local, uma vez que essa está associada às ações e influências de inúmeros outros elementos humanos e não-humanos. Assim, ao se ponderar que, na ANT, ocorre uma difusão de associações, as mediações resultantes do agir participativo no processo de TBC não abarcariam somente as próprias comunidades locais.

Portanto, não se poderia perder de vista, nesta análise, que outros grupos humanos e instituições compõem o coletivo na Rede, como os porta-vozes das ONG, dos movimentos sociais, das universidades, da cooperação italiana, da especulação imobiliária, além de turistas, agências e operadoras de viagens, "amigos da rede" e gestores públicos. Nesse sentido, é importante observar de que forma esses grupos mobilizam os elementos não-humanos, bem como em que medida esses últimos intervêm nas mediações negociadas. Portanto, todos os atores deixam rastros no caminho e proporcionam informação sobre como o TBC se constrói e se reconstrói ao longo do tempo e do próprio processo.

Nesse contexto, quais são as associações possíveis entre os múltiplos atores no TBC que deveriam ainda ser examinadas? Quem age e faz agir nessa prática? Quais são as ações empreendidas permanentemente? Reconhecer e sustentar essas incertezas no processo permitiria uma compreensão ainda mais ampla sobre o TBC a partir da reafirmação das diferentes vozes e enunciados, e não somente na versão das próprias comunidades envolvidas, entendidas, até então, como as protagonistas do processo.

Assim, reconhecendo essas e outras indagações decorrentes da pesquisa que inspirou o presente artigo, é possível também apreender que o turismo comunitário propicia o fazer política, o que culminou na criação da Rede. Ou seja, a Rede foi construída para funcionar, também, como um tipo de proteção para o turismo comunitário na ZCC. De forma situada, o turismo comunitário está associado à Rede, e vice-versa, tecendo uma força híbrida de turismo comunitário-Rede.

A partir do reconhecimento das associações entre os elementos humanos e não-humanos para a constituição do coletivo pode-se, então, assegurar um posicionamento em pesquisa não influenciado pela hierarquização desses elementos no processo investigativo em TBC. 


\section{c) O TBC em ação}

A partir dos aportes da ANT e, principalmente, do reconhecimento da importância dos elementos não-humanos e da produção de associações na dinâmica turística, foi possível refletir sobre o TBC enquanto uma rede de atores em ação. Essa perspectiva reafirmou a compreensão do TBC na Rede.

Nesse sentido, este exercício pressupôs uma mudança de posição epistemológica com relação à própria leitura da realidade investigada na Rede, uma vez que as dinâmicas de TBC não se reduzem a um contexto no qual a vida acontece e tudo se enquadra no que está preestabelecido. Pelo contrário, pela ótica da ANT, essas dinâmicas envolvem interesses que foram rastreados empiricamente, em um movimento permanente que constrói e reconstrói os caminhos trilhados pelos variados atores e suas associações. Foram assim identificados outros atores e formadas novas associações, as quais foram novamente reagregadas em um movimento contínuo.

A perspectiva de análise da ANT implicou a compreensão do "TBC em ação" na Rede, o que se traduz como a síntese de uma condição permanente de construção negociada dessa prática, sujeita a controvérsias. Portanto, o TBC não poderia ser decodificado linearmente em manuais herméticos, homogeneizantes, totalizantes e adotados como padrão para o direcionamento do processo. Também não seria o caso de se analisar o "produto" de TBC formatado. Pelo contrário, privilegia-se a descrição do movimento de construção e reconstrução que delineia, em múltiplas versões, o TBC.

A pista da ANT de seguir os atores implica o afastamento de qualquer visão idealizada do TBC e o lança à análise da ação. Este não poderia ser reduzido a uma tipologia ou segmento turístico, nem tampouco a uma alternativa de turismo, conforme vem sendo o caso de vias usuais de análise sobre o tema. A partir desse entendimento, poder-se-ia delinear compreensões alternativas de TBC para uma composição mais ampla. Isso porque, no caso da Rede, cada grupo produz um turismo comunitário particular, reagregando e renovando a existência da sua própria prática. O turismo comunitário praticado nas comunidades pesqueiras é, assim, diferente do praticado na terra indígena ou nos assentamentos rurais, entre outros locais da ZCC. Algumas experiências associadas ao turismo comunitário - e também ao turismo sustentável e rural -, que são igualmente influenciadas pelas práticas do turismo de massa são mais valorizadas do que outras. Dessa forma, todas essas práticas fazem parte do coletivo e são permeadas por controvérsias. 
Segundo as pistas da ANT, no caso empírico da Rede, foi possível reafirmar ainda que o TBC tende a se traduzir como um efeito de múltiplas redes de atores em ação que ora se estabilizam, ora se renovam. Desta forma, foi possível acompanhar o modo de concepção dos processos de articulação do TBC na Rede, que se reconstrói a partir de estratégias políticas negociadas pelas diversas partes envolvidas, dentre as quais se destacam: (a) promoção de uma assembleia anual; (b) participação em editais de fomento de instituições públicas e privadas e de organizações não governamentais no Brasil e no exterior; (c) formação contínua do grupo de turismo comunitário local; (d) articulação com outras redes e fóruns aliados; (e) elaboração do Caderno de Normas e Procedimentos Internos; (f) discussão sobre políticas públicas e articulação de agenda com gestores públicos; (g) promoção de intercâmbios em TBC; (h) preparação e divulgação de pacotes temáticos e integrados entre comunidades da Rede; (i) criação da Escola Popular de Turismo Comunitário; (j) realização de campanhas e acampamentos da juventude, entre outras.

Portanto, os estudos com enfoque em TBC, sob a inspiração da ANT, tendem a contribuir para revelar o coletivo complexo de discursos e práticas que, incessantemente, articulam-se e tecem redes, a partir das associações entre humanos e não-humanos. Vale ressaltar, ainda, que essas articulações, movidas por jogos de interesse e de poder, podem ser interrompidas, embaraçadas, suspensas e desviadas por incertezas a todo instante, produzindo uma dinâmica particular na composição do TBC em ação.

\section{Considerações finais}

A presente reflexão sobre novos caminhos investigativos com relação ao TBC no Brasil, percorridos à luz da ANT, traduz um movimento ainda em construção na pesquisa acadêmica. Nesse sentido, buscou-se articular algumas proposições teórico-metodológicas da ANT como um caminho fértil para contribuir e ampliar a compreensão sobre as dinâmicas do TBC na perspectiva prática da Rede TUCUM, considerando-se, nesse percurso, as pistas investigativas relacionadas aos elementos não-humanos, às associações e aos atores em ação.

A partir desta leitura, buscou-se argumentar que o TBC, em realidade, se configura como "efeito" de uma rede sociotécnica, que traduz uma complexa trama de elementos heterogêneos em ação que, por sua vez, manifestam-se nos modos de existência de grupos que não são simplesmente "sociais", uma vez que, nessa dinâmica, operam também elementos não-humanos. Ou seja, todos os atores são simultaneamente sociais e técnicos, 
o que demanda uma análise complexa sobre o objeto em foco, que os considere na mesma hierarquia.

Nesse sentido, as práticas e enunciados de TBC são tecidos por ações de inúmeros grupos humanos, que, no caso da Rede TUCUM, envolvem pescadores artesanais, etnias indígenas, agricultores familiares, assentados rurais e quilombolas, entre outros, mas também os elementos não-humanos que atuam na construção dessa dinâmica. Por essa razão, estudar esses grupos à luz da ANT implicou reconhecer as peculiaridades, em termos vivenciais, das suas relações com a terra, o mar, a agricultura, a pesca e o artesanato, entre outras práticas que têm força para mobilizar ações no contexto do desenvolvimento local. Por esse ângulo, a dinâmica local é influenciada, também, pelos interesses e iniciativas de ONG, movimentos sociais, instituições de ensino superior, órgãos da gestão pública, agências e operadoras de viagens, entre outros atores.

Assim, quanto melhor for apreendida e traduzida a multiplicidade de atores envolvidos, mais compreensível tende a ser o estudo sobre a constituição da rede sociotécnica de TBC, sendo essa uma questão ontológica. Seguindo os atores e suas conexões e, ainda, apostando em uma composição polifônica dos discursos e vozes rastreados, esta análise possibilitou uma "viagem" de aprendizagem na coprodução de uma forma de se pesquisar o TBC, que exigiu novas ferramentas.

Em outras palavras, o estudo do TBC na Rede TUCUM foi explorado sem buscar enquadrá-lo em "molduras teóricas" pré-estabelecidas, conforme orientação da ANT. Esse desafio exigiu a ousadia de sair da zona de conforto e abrir a "caixa de conceitos", permitindo que o próprio campo indicasse e movesse as questões inspiradoras da pesquisa. Além disso, essa posição epistemológica viabilizou a produção de novas descrições sobre o tema sem estabilizá-lo, o que gerou uma compreensão ampliada sobre as inúmeras questões e impasses envolvidos nessa imersão que só puderam ser respondidos no campo da pesquisa.

Nessa perspectiva antropológica buscou-se descrever a vivência empírica do objeto de interesse em um movimento de pesquisa que se faz "com" e não "sobre" os atores rastreados, apreendendo a complexidade e a realidade do que se pesquisa em constante diálogo com diferentes saberes. Esse contexto aponta, de tal modo, para que se proceda, no Brasil, a uma exigência ética de pesquisa, não apenas protocolar mas que se afirme também como local e situada.

Revisto por Sofia Silva 


\section{Referências bibliográficas}

Akrich, Madeleine; Callon, Michel; Latour, Bruno (2006), Sociologie de la traduction: textes fondateurs. Paris: Presses des Mines.

Bartholo, Roberto; Sansolo, Davis; Bursztyn, Ivan (2009), Turismo de base comunitária: diversidade de olhares e experiências brasileiras. Rio de Janeiro: Letra e Imagem.

Brasil (2008), "Edital de chamada pública de projetos Mtur/nº 001/2008 - Seleção de propostas de projetos para apoio às iniciativas de turismo de base comunitária". Brasília: Ministério do Turismo.

Cañada, Ernest (2015), "La comercialización internacional del turismo comunitario. La experiencia en América Latina”, $A R A, 5(2), 23-47$.

Coriolano, Luzia Neide Menezes Teixeira; Lima, Luiz Cruz (2003), Turismo comunitário e responsabilidade socioambiental. Fortaleza: EDUECE.

Dedeke, Adenekan Nick (2017), "Creating Sustainable Tourism Ventures in Protected Areas: An Actor Network Theory Analysis”, Tourism Management, 61, 161-172.

Fabrino, Nathália Hallack (2013), "Turismo de base comunitária: dos conceitos às práticas e das práticas aos conceitos”. Dissertação de Mestrado em Desenvolvimento Sustentável, Centro de Desenvolvimento Sustentável, Universidade de Brasília, Brasília, Brasil.

Irving, Marta de Azevedo (2009), "Reinventando a reflexão sobre turismo de base comunitária: inovar é possível?”, in Roberto Bartholo; Davis Sansolo; Ivan Bursztyn (orgs.), Turismo de base comunitária: diversidade de olhares e experiências brasileiras. Rio de Janeiro: Letra e Imagem, 108-121.

Latour, Bruno (2002), Reflexão sobre o culto moderno dos deuses fe(i)tiches. Bauru: EDUSC. Tradução de Sandra Moreira.

Latour, Bruno (2004), Políticas da natureza: como fazer ciência na democracia. Bauru: EDUSC. Tradução de Carlos Aurélio Mota de Souza.

Latour, Bruno (2012), Reagregando o social: uma introdução à teoria do ator-rede. Salvador/São Paulo: EDUFBA/EDUSC. Tradução de Gilson César Cardoso de Sousa.

Latour, Bruno (2013), Jamais fomos modernos: ensaio de antropologia simétrica. Rio de Janeiro: Editora 34 [3. a ed.]. Tradução de Carlos Irineu da Costa.

Lima, Luiz Cruz; Coriolano, Luzia Neide Menezes Teixeira (orgs.) (2003), Turismo e desenvolvimento social sustentável. Fortaleza: EDUECE.

Lima, Robson Pereira (2011), "Turismo de base comunitária como inovação social". Tese de Doutorado em Engenharia de Produção, Universidade Federal do Rio de Janeiro, Rio de Janeiro, Brasil.

Maldonado, Carlos (2009), "O turismo rural comunitário na América Latina: gênesis, características e políticas”, in Roberto Bartholo; Davis Sansolo; Ivan Bursztyn (orgs.), Turismo de base comunitária: diversidade de olhares e experiências brasileiras. Rio de Janeiro: Letra e Imagem, 25-44. 
Martins, Rosa (org.) (2013), "Caderno de normas e procedimentos internos da Rede Tucum - Rede Cearense de Turismo Comunitário”. Fortaleza: Rede TUCUM/ /Instituto Terramar.

Mendonça, Teresa Cristina de Miranda; Lima, Patrícia Isabela; Moraes, Ana Paula Veríssimo de; Oliveira, Jefferson Carvalho de (2014), "O estado da arte do turismo de base comunitária no litoral do Estado do Rio de Janeiro: abordagem téorico-conceitual, político-organizacional e iniciativas em curso”. Nova Iguaçu: UFRRJ.

Mendonça, Teresa Cristina de Miranda; Irving, Marta de Azevedo (2004), "Turismo de base comunitária: a participação como prática no desenvolvimento de projetos turístico no Brasil - Prainha do Canto Verde, Beberibe (CE)", Caderno Virtual de Turismo, 4(4), 12-22.

Mielke, Eduardo Jorge Costa (2010), Desenvolvimento turístico de base comunitária: uma abordagem prática e sustentável. Campinas: Alínea.

Moraes, Edilaine Albertino de (2019), "Siga os atores e as suas próprias ações: nos rastros das controvérsias sociotécnicas do turismo de base comunitária na Rede TUCUM - Ceará - Brasil”. Tese de Doutorado em Psicossociologia de Comunidades e Ecologia Social, Instituto de Psicologia, Universidade Federal do Rio de Janeiro, Rio de Janeiro, Brasil.

Moraes, Edilaine Albertino de; Irving, Marta de Azevedo (2018), "Turismo de base comunitária: entre utopias e caminhos possíveis no contexto brasileiro”, in Marta de Azevedo Irving; Julia Azevedo; Marcelo Augusto Lima (orgs.), Turismo: ressignificando sustentabilidade. Rio de Janeiro: Folio Digital/Letra e Imagem, 317-345.

Moraes, Edilaine Albertino de; Irving, Marta de Azevedo; Mendonça, Teresa Cristina de Miranda (2018), "Turismo de base comunitária na América Latina: uma estratégia em rede”, Revista de Turismo Visão e Ação, 20(2), 249-265.

Netto, Alexandre Panosso (2011), Filosofia do turismo: teoria e epistemologia. São Paulo: Aleph [2. ${ }^{a}$ ed. revista e ampliada].

Novo, Cristiane Barroncas Maciel Costa; Cruz, Jocilene Gomes da (orgs.) (2014), Turismo comunitário: reflexões no contexto amazônico. Manaus: EDUA.

Pedro, Rosa (2010), "Sobre redes e controvérsias: ferramentas para compor cartografias psicossociais”, in Arthur Ferreira; Letícia Freire; Márcia Moraes; Ronald Arendt (orgs.), Teoria ator-rede e psicologia. Rio de Janeiro: Nau, 78-96.

Rodger, Kate; Moore, Susan A.; Newsome, David (2009), "Wildlife Tourism, Science and Actor Network Theory", Annals of Tourism Research, 36(4), 645-666.

Sampaio, Carlos Alberto Cioce (2011), "Perspectiva do turismo comunitário, solidário e sustentável”, in Carlos Sampaio; Christian Henríquez; Cristiane Mansur (orgs.), Turismo comunitário, solidário e sustentável. Blumenau: EDIFURB, 23-30.

Santiago, Maria Cristina de Sousa (2015), “Turismo de base comunitária: perspectivas teórico-conceituais presentes no livro 'Turismo de base comunitária: diversidade de olhares e experiências brasileiras'”. Trabalho de conclusão de curso da 
Licenciatura em Turismo, Universidade Federal Rural do Rio de Janeiro, Nova Iguaçu, Brasil.

Silva, Jefferson Souza da (org.) (2008), Anais do II Seminário Internacional de Turismo Sustentável. Fortaleza: Instituto Terramar/Fórum em Defesa da Zona Costeira.

Silva, Kátia; Ramiro, Rodrigo; Teixeira, Breno (2009), "Fomento ao turismo de base comunitária: a experiência do Ministério do Turismo", in Roberto Bartholo; Davis Sansolo; Ivan Bursztyn (orgs.), Turismo de base comunitária: diversidade de olbares e experiências brasileiras. Rio de Janeiro: Letra e Imagem, 359-373.

Scharer, René (2015), "Economia solidária e turismo de base comunitária - Uma experiência brasileira”, in Sidney Lianza (org.), PAPESCA em Ação II. Rio de Janeiro: Soltec/UFRJ, 60-67.

TUCUM (2010), "Relatório técnico da $4^{a}$ Assembleia Anual da Rede TUCUM". Fortaleza: Instituto Terramar.

van der Duim, René (2005), "Tourismscapes. An Actor-Network Perspective on Sustainable Tourism Development”. Tese de Doutorado em Geografia, Wageningen University \& Research, Wageningen, Nederland. van der Duim, René; Ren, Carina; Jóhannesson, Gunnar Thór (2012), Actor-Network

Theory and Tourism: Ordering, Materiality and Multiplicity. United Kingdom: Routledge [1. ${ }^{a}$ ed.].

Artigo recebido a 13.01.2019

Aprovado para publicação a 27.03.2020

\section{Edilaine Albertino de Moraes}

Instituto de Ciências Humanas, Departamento de Turismo da Universidade Federal de Juiz de Fora Campus Universitário, Rua José Lourenço Kelmer, s/n, São Pedro, CEP: 36036-900 Juiz de Fora, Minas Gerais, Brasil Contacto: edilaineturmoraes@hotmail.com ORCID: https://orcid.org/0000-0001-7631-5023

\section{Marta de Azevedo Irving}

Instituto de Psicologia, Programa de Pós-graduação em Psicossociologia de Comunidades e Ecologia Social da Universidade Federal do Rio de Janeiro Av. Pasteur, 250, Pavilhão Nilton Campos, CEP: 22290-240 Praia Vermelha, Rio de Janeiro, Brasil Contacto: mirving@mandic.com.br ORCID: https://orcid.org/0000-0003-2677-818X 


\section{Rosa Maria Leite Ribeiro Pedro}

Instituto de Psicologia, Programa de Pós-graduação em Psicologia da Universidade Federal do Rio de Janeiro

Av. Pasteur, 250, Pavilhão Nilton Campos, CEP: 22290-240 Praia Vermelha, Rio de Janeiro, Brasil Contacto: rosapedro@globo.com

ORCID: http://orcid.org/0000-0002-3476-790X

\section{Elizabeth Oliveira}

Instituto Nacional de Ciência e Tecnologia em Políticas Públicas, Estratégias e Desenvolvimento da Universidade Federal do Rio de Janeiro (bolsista CAPES)

Av. Pasteur, 250, Instituto de Economia da UFRJ, Palácio Universitário,

CEP: 22.290-902 Praia Vermelha, Rio de Janeiro, Brasil

Contacto: elizabetholiverbr@gmail.com

ORCID: http://orcid.org/0000-0003-0895-3108

\section{Community-Based Tourism Inspired by Actor-Network Theory: New Investigative Paths in the Brazilian \\ Context}

This article focuses on the need for a new theoretical and conceptual problematization of community-based tourism or community tourism (CBT) in Brazil, exploring the actor-network theory as a possible analytical tool in this direction. To this end, contributions to this reflection will be made through a brief report of the empirical research, developed in the Community Tourism Network of Ceará (TUCUM - Brazil), to describe its dynamics of articulation and composition of the CBT. From this perspective, it was possible to identify non-human elements that operate in this network of actors. The study also signaled the importance of the concept of association for tracking multiple possible connections between the actors involved in the TUCUM Network's CBT. Thus, the actor-network theory made it possible to analyze the dynamics of the CBT, underlining the movements of reinvention of this Brazilian practice.

Keywords: actor-network theory; Brazil; community tourism.

\section{Tourisme de base communautaire à la lumière de la théorie de l'acteur- -réseau: des nouvelles voies de recherche dans le contexte brésilien}

Cet article met l'accent sur la nécessité d'une nouvelle problématisation théorique et conceptuelle du tourisme de base communautaire ou tourisme communautaire (TBC) au Brésil, en explorant la théorie de l'acteur-réseau comme une voie possible en ce sens. À cette fin, il se propose de contribuer à cette réflexion par un bref rapport de la recherche empirique développée dans le Réseau de tourisme communautaire du Ceará (TUCUM-Brésil), dans le but de décrire ses dynamiques d'articulation et de composition du TBC. De ce point de vue, il a été possible d'identifier les éléments non-humains qui opèrent dans ce réseau d'acteurs. Létude a également signalél'importance du concept d'association pour le suivi de multiples connexions possibles entre les acteurs impliqués dans le TBC, dans le réseau TUCUM. Ainsi, la théorie de l'acteur-réseau a permis d'analyser les dynamiques du TBC, soulignant les mouvements de réinvention de cette pratique dans le contexte brésilien. Mots-clés: Brésil; théorie de l'acteur-réseau; tourisme communautaire. 